\title{
From The Office To The Gym Without Pain Informative guide for the fitness professional
}

ABSTRACT: Most people today live a sedentary lifestyle, sitting for 10 to 12 hours a day. Consequently they become less and less conditioned and equipped to take part in recreational and sports activities in or outdoors. Technological advances mean we are required to move less and less, leading to loss of range of motion (ROM) and postural deviations. Some muscles have the tendency to become underactive and others to become overactive (Kendall et al, 2005, Page, 2010). Physical inactivity is increasing the risk of musculoskeletal problems (Holth, 2008, Page, 2010, Davies, 2014), which eventually manifest in pain. This means that working with today's typical client and athlete is becoming increasingly challenging for personal trainers and sports coaches. The NASM Corrective Exercise Continuum (CEx) is a systematic, corrective program that is based on deactivation and activation techniques of the muscle and fascia tissue. I used this system extensively with clients, which enabled them to eliminate minor problems associated with muscle imbalances and some managed to keep major musculoskeletal problems under control so they haven't experienced pain. Best to use the CEx system in conjunction with body and postural awareness techniques. My overall aim is to draw attention to some movement and range of motion (ROM) dysfunctions that are warning signs of potential pain development. In line with the CEx system, I will suggest some easy to implement techniques and exercises to improve muscle quality and activity, thereby reducing the risk of injuries outdoors or in the gym.

Keywords: Sedentary lifestyle, joint range of motion, warm-up, injury prevention, the NASM Corrective Exercise Continuum

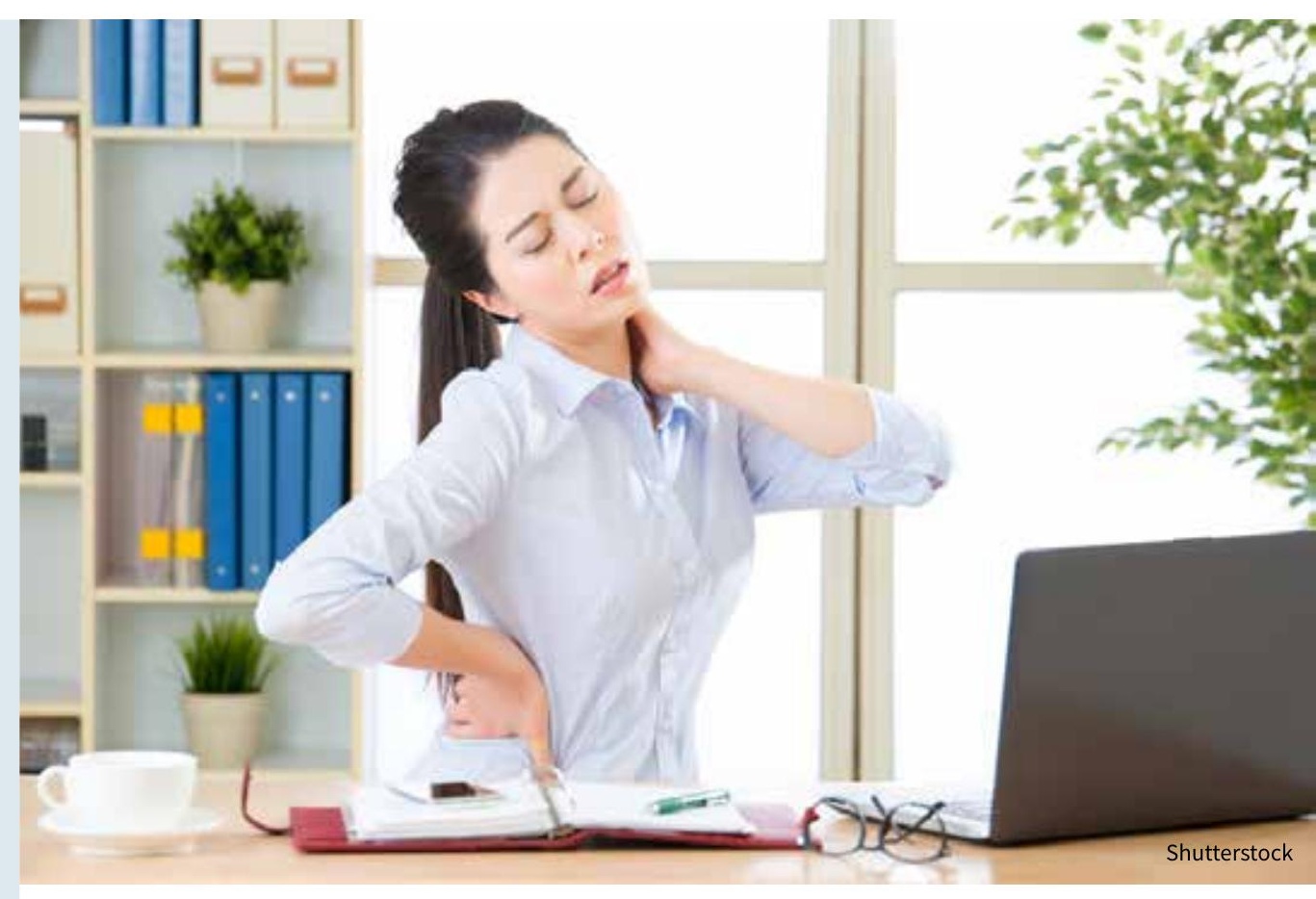

\section{Introduction}

Over the last twelve years I have spent over 10,000 hours helping people in their training, from those new to the gym to accomplished athletes, many of whom have come to me suffering with musculoskeletal pain or an existing injury. Most of these problems could have been tracked down to lack of flexibility and abnormal stresses on certain joints and surrounding structures (Page et al, 2010). Although some of these pains can be caused by age related degeneration (Machado de Rezende et al 2014), as certain activities can cause wear and tear over time, the underlying problem is often the accumulative overload of muscles through repetitive movements, inappropriate footwear and adopting a poor sitting posture every day

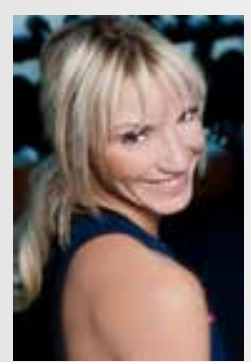

Szerző, rovatvezetō:

Ressinka Judit

Cégtulajdonos,

Személyi Edzõ

HIIT Csoportos edzõ

FIT360 Fitnesz Stúdió Kft.

1135 Budapest, Lehel utca 64.

E.ép.

http://www.fit360fitness.hu

(+36) 70-6087848

edzes@fit360fitness.hu

Föbb kutatási területei:

fájdalommentes mozgás (Grimmer, 2000, Murphy et al, 2004). Lack of stretching and regular muscle activation by just getting up from the table regularly can worsen the effects several folds. While some clients may cycle to work, go for a jog, swim or go to the gym after work they are often doing these activities with bad posture and joint alignment, and without stretching or warming-up, adding to the underlying problems that eventually will manifest as pain (Figure 1).

\section{Most common pain areas:}

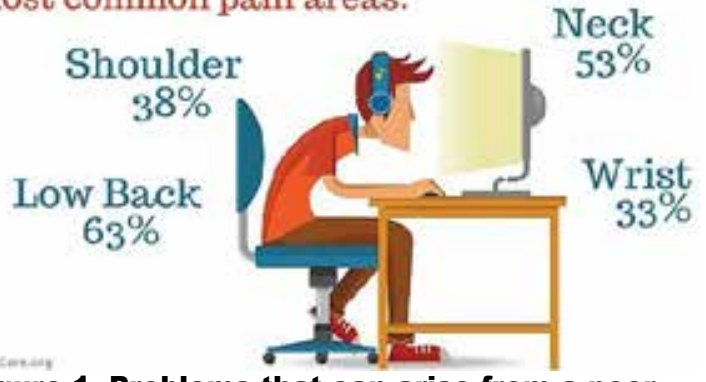

Figure 1. Problems that can arise from a poor sitting posture 


\section{Movement}

\section{Assessments}

\section{Prior Choosing the}

\section{Corrective Exercises}

What can a trainer do then when a client with potential musculoskeletal problems approaches them for the first time? For one, in a free consultation the trainer can build trust, gather information and perform functional movement tests on the clients. A series of questions can be asked about the client's work, their typical day, as well as their medical, pain and exercise history. As a second step, the trainer can assess movement, screen for abnormalities, particularly with the overhead squat (Hirth, 2007) and the single leg squat (Diamattia et al, 2005, Crossley et al, 2011)(Figure 2). Functional assessment should be incorporated into pre-participation screening in order to determine whether a client has the essential movement, mobility and strength to perform certain activities (Gray et al, 2010). Observation of movement can highlight common movement dysfunctions, ROM limitations and can also be used to develop strategies for the prevention of injuries and enhancement of athletic performance (Ford et al, 2003, Clark et al., 2011, Yu et al, 2005, Gray et al, 2010).

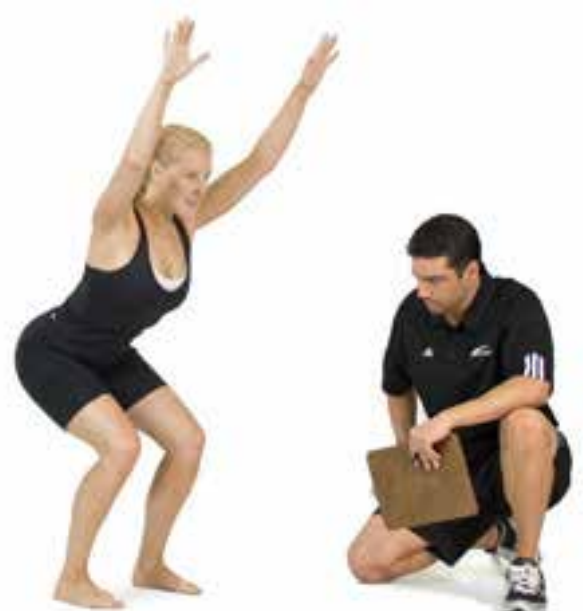

Figure 2. Movement assessment the overhead squat (NASM)

Step three, if after the movement screen, I suspect weakness I test a muscle for strength (Kendall, 2006). Then based on what I have heard and seen I write an initial program. Finally, step four incorporates corrective work for the observed movement dysfunction. I assess other dynamic movements such as pushing, pulling, rotation, mobility and stability within our first few sessions using the NASM (Clark, 2011) and Functional Movement Screen (FMS) tests and further refine the program based on the results (Gray et al,
2010) to achieve maximum benefit. I also reassess clients' movement by repeating steps one to three from time to time.

The two movement assessment programs, NASM and FMS, are the first to provide functional evaluation standards and corrective solutions since 1987 and 1998, respectively. These screening methods are bridging the gap between fitness professionals and clinical practitioners such as physiotherapists. Both systems require a thorough understanding of the musculoskeletal system and so are designed for use by personal trainers and coaches. Both systems are based on knowledge from renowned experts such as Vladimir Janda, Shirley Sharmann, Florence Peterson Kendall and Elizbeth Kendall McCreary. These specialists all agreed that due to occupational and postural strains, certain muscles get chronically lengthened and others chronically shortened therefore they develop weakness or overactivity.

\section{Need for the}

\section{deactivation-activation steps: Typically weak} and overactive muscles

Some muscles have a tendency to get tight or overactive - these muscles generally have one third greater strength than those which tend to get weakened (Page, 2010). Through a mechanism called reciprocal inhibition, these tight or overactive muscles will inhibit the antagonist muscles, on the opposite side of the same joint, which in turn can appear to be weak when tested or these antagonist muscles can get overly lengthened therefore unable to contract properly.

Typical weakness and underactivity that can be found in the lower extrem- ity are - for example the bottom's muscles (the gluteus maximus, the gluteus medius), the abdominals (TVA) and core muscles - while the hip flexors (iliopsoas, rectus femoris) and the lower back's erector spinae show tightness. In the upper extremity, the posterior deltoid (rear shoulder), and the middle and lower trapezius, rhomboids and serratus anterior prone to becoming lengthened and weak, while the upper trapezius and levator scapulae along the chest muscles become tight. Figure 3.a,b display the imbalanced muscular patterns which had been classified as Upper-Crossed and Lower-Crossed Syndrome (Janda, 1987) (Figure 3).

Once a muscle imbalance exists, shortened or overactive muscles will force the joint out of alignment, causing joint dysfunction, poor movement patterns and compensation elsewhere. This cascade of events will start an underlying pathology well before the pain presents itself (Janda 1987, 1993). When compensation occurs, certain muscles will take over as the prime movers, which under normal circumstances should only assist the prime movers. For example, consider the hip flexor muscles, the psoas. When someone spends long hours sitting, this muscle remains in a shortened position for too long and eventually it remains that way if it is not stretched properly. This tight muscle will reciprocally inhibit the gluteus maximus muscle (Figure 3.a) The gluteus maximus will have altered force production - it will be delayed acting as a prime mover for hip extension (straightening the hip) which will lead to a substitution of its role by the upper thigh and the lower back muscles. If this imbalance and altered recruitment continues over a prolonged period of time, hamstring pain and lower back pain will develop.

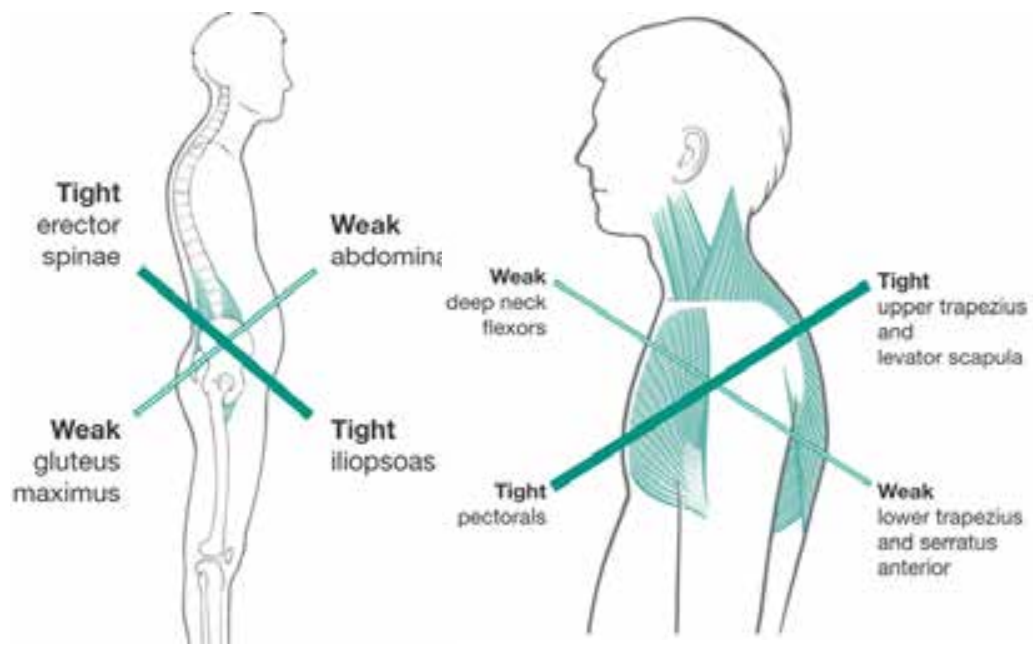

Figure 3. Impairment syndromes of the lower (a) and the upper (b) body (Janda, 1987) 


\section{Corrective Strategy: NASM CEX}

Most people who train recreationally assume that a general warm-up only includes stretching and raising the heart rate. This will confer the following benefits: reduced muscle stiffness, greater oxygen flow to the working muscles, increased body temperature, decreased muscle viscosity, increased muscle contraction times and increased lubrication of the joints. However, an effective warm-up also needs to negate the effects of lifestyle, by deactivating muscles that are overactive and activating those that are inhibited/underactive.

The NASM CEx system (Figure 4) recognises this and puts forward a warm-up model that includes the following four steps for muscle function: 1) Inhibit 2) Stretch 3) Activate 4) Integrate. The first three steps should precede any other warm-up component as they aim to correct muscle dysfunctions before other activity takes place. The fourth step can be incorporated into the workout itself.

1) Inhibitory Techniques (Figure 5.a) - These techniques release tension or decrease overactivity, not just in the muscle but in the neuromyofascial (nerve-muscle-fascia) tissues of the body. They include Self-Myofascial Release (SMR) which is a self-massage therapy, releasing the trigger points of overworked, tender muscles and fascia (Page, 2010). SMR can be performed using foam rollers, sacrosse balls or tennis balls.

2) Lengthening Techniques (5.b) Static stretching (SS) and proprioceptive neuromuscular facilitation (PNF) are used to increase the length of the neuromyofascial tissues.

3) Activation Techniques (5.c) Once the release and lengthening of tight muscles has been achieved, acti-

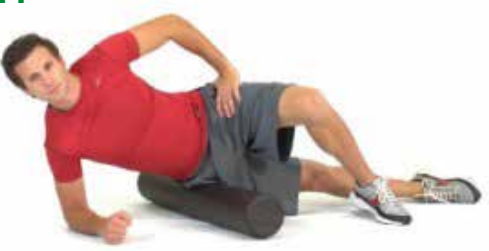

5.a Inhibit

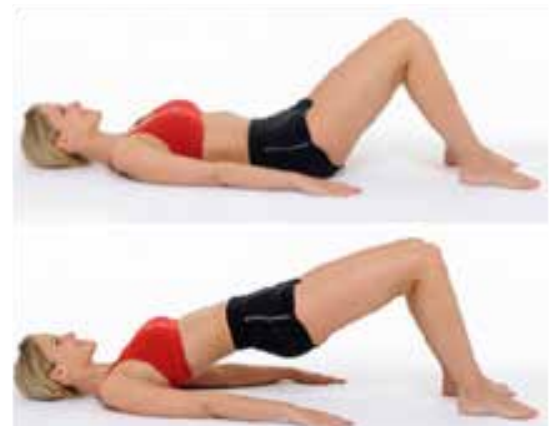

5.c Activate

\section{Figure 5. The NASM CEx system warm-up model}

vation can be done through isolation exercises. These involve only one joint and a limited number of muscle groups, so that more attention can be paid to ensuring the muscle's sufficient contraction - thereby avoiding using the overactive, 'cheating' muscles. Isolation exercises are slow and controlled motions.

4) Integration Techniques (5.d) - These are how a client can relearn movement with the correct order of muscles firing. Integration techniques retrain the activated muscles through functional movements such as weighted total-body exercises.

\section{Stretching pre- exercise: Good or bad}

Stretching is a controversial topic among performance coaches. There is little, if any, evidence that SS and PNF pre-participation prevents injury, as was previously thought (Paradisis 2014,

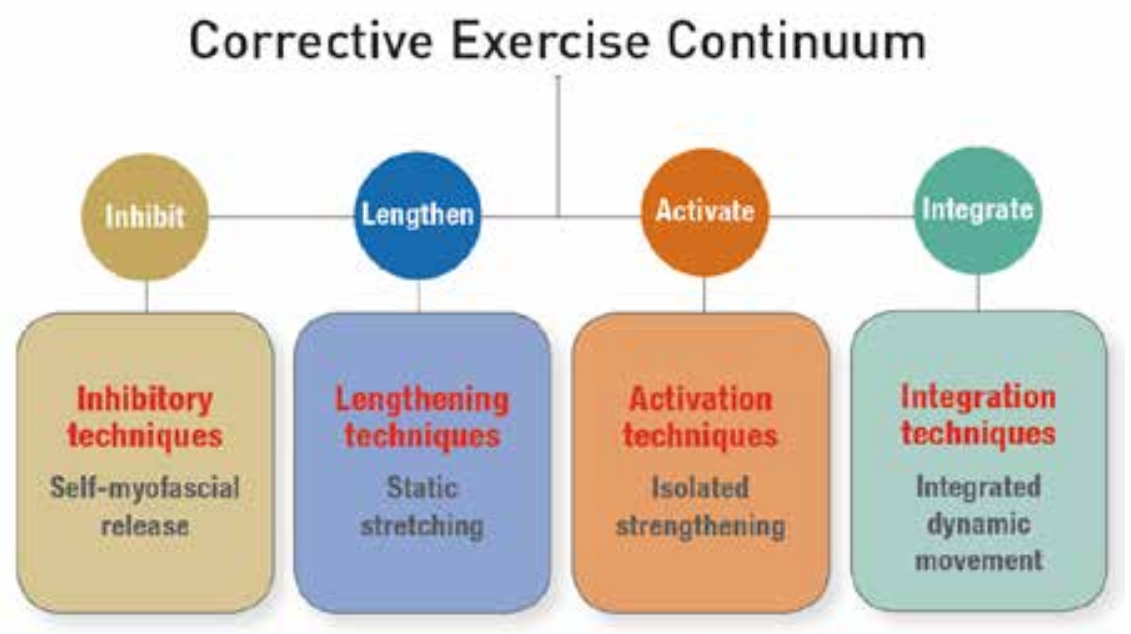

Gergley 2013). Also, growing evidence suggests that SS has no or a detrimental effect on subsequent performance as it has been shown to lead to a decrease in force production, power performance, running speed, reaction and strength endurance in athletes (Marek, 2005, Haag, 2010, Gergley, 2013, Haddad, 2014, Paradisis, 2014). However, the average recreational athlete needs to increase ROM around several joints to avoid accumulative injuries. Research shows that decreased flexibility, below normal ranges, can lead to $2.5 \mathrm{x}$ increased injury risk (Pope 1998). Also it is important to note that long-term studies on static stretching protocols show that SS leads to decreased chronic injury rates (Pope, 1998, Amako, 2003, Wilson, 2010).

Dynamic stretching (DS), on the other hand, has been shown to improve subsequent running performance in both acute and chronic cases (Ramachandran, 2014, Judge, 2009) and can help decrease the effects of performance decline caused by SS. Therefore, SS is conducted prior to subsequent higher intensity dynamic warm-up elements, it is likely that its detrimental effects will be diminished. In a CEx programme, SS should be applied to muscles that have been determined to be overactive or tight.

\section{The reason why trigger points need to be eliminated}

Symptoms such as weakness, decreased ROM and early fatigue in the muscles can also be caused by trigger

Figure 4. The Corrective Exercise Continuum (Clark, 2011). 
points (TrPs) (Page, 2010, Mense and Simons, 2001), which develop as the bands of muscle fibers get overstimulated. One way to overload a muscle is by placing it in a shortened or lengthened position again and again over a period of time. This can happen after an injury as a person tries to avoid pain, and carries itself asymmetrically or it can happen due to degenerative postural overload when a person is constantly hunching over their desk causing the head to fall forward, the shoulders to round and the back to hunch.

TrPs can be palpated as hypersensitive nodules of muscle fibers. Pressure on the TrP will cause pain in the affected area or the pain can radiate to other areas. In my experience, clients typically have significant pain on palpation in the muscles that serve to maintain body posture, such as muscles in the neck, shoulders and pelvic girdle, due to repetitive overload at work, in the car or at home. TrPs may also manifest as a tension headache, or as neck, calf and lower back pain (Alvarez, 2002). (Figure 6). I will revisit common TrPs due to postural deviation later on in this series of articles, focusing on particular body parts and where they refer pain.

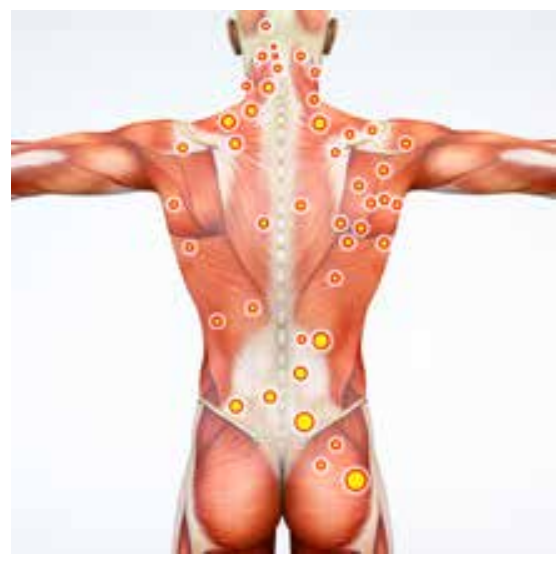

Figure 6. Most frequent location of trigger points in the upper body posterior view.

\section{Conclusions}

It is important to warm up before recreational and sport activities. In accordance with the literature, there is a need to deactivate overactive muscles, before the antagonist muscles that they reciprocally inhibit, can get activated. The NASM CEx system is an effective system in activating and deactivating muscles. As discussed an inhibited, weak muscle can't fulfill its function and this eventually will cause permanent muscle imbalances and structural changes to occur such as the lowercrossed and upper-crossed syndromes. It was established that static stretching is needed with the general population, the performance decreasing effects will dissipate with time or dynamic stretching can be used to eliminate any negative effects. Trigger points further weaken the muscle and fascia therefore the use of self-myofascial release is recommended. The activation and integration of muscles is a pre-requisite to any exercise routine. From my own experience with clients, I know that these techniques can be learnt and used by any client regardless of age.

\section{Summary}

The tools and solutions put forward by the NASM CEx address muscular imbalances, tightness and weakness. They provide an innovative, research-based and systematic approach that builds effectively on previous techniques and appears to tackle problematic areas. In my experience, NASM CEx works best and has greater carry-over effect to everyday life when clients are educated about posture and correct movement during daily activities such as sitting, walking and sleeping.

\section{References:}

Alvarez D.J. \& Rockwell P.G. (2002) Trigger Points: Diagnosis and Management. Am Fam Physician. 65(4):653-661.

Amako M1, Oda T, Masuoka K, Yokoi H, Campisi P. (2003): Effect of static stretching on prevention of injuries for military recruits. Mil Med. 168(6):442-6.

Brodowitcz G.R., Welsh R., Wallis J. (1996): Comparison of stretching with ice, stretching heat, or stretching alone on hamstring flexibility. J Athl Train. 31:324-7. Clark M.A. \& Lucett S.C. (2011): NASM Essentials of Corrective Exercise Training. Lippincott Williams \& Wilkins, United States. P108-139.

Crossley K.M., Zhang W.J., Schache A.G., Bryant A., and Cowan S.M. (2011): Performance on the single-leg squat task indicates hip abductor muscle function. Am J Sports Med. 39(4):866-873.

Davies, S.C., McBride, M., Keel, A, Hussey R. (2014): Musculoskeletal health: Public Health Approach. www.arthritisresearchuk.org/ /media/Files/.../publichealth-guide.ashx

Dimattia M.A., Livengood A.L., Uhl T.L., Mattacola C.G., Malone T.R. (2005): What are the validity of the single-leg squat test and its relationship to hip abduction strength. $J$ Sport Rehabil. 14:2; 108-123.

Ford K.R., Myer G.D., Hewett T.E. (2003): Valgus knee motion during landing in high school female and male basketball players. Med Sci Sports Exerc. 35(10):1745-1750.

Ramachandran S., and Pradhan B. (2014): Effects of short-term two weeks low intensity plyometrics combined with dynamic stretching training in improving vertical jump height and agility on traine basketball players. Indian J Physiol Pharmacol. 58(2):133-6.
Fragala M.S., Thomas G.A. Anderson J.M. Hakkinen K., and MAresh C.M. (2008): Effects of stretching on upper-body muscular performance. J Strength Cond Res. 22:1279-1285.

Gergley J.C. (2013): Acute effect of passive static stretching on lower-body strength in moderately trained men. J Strength Cond Res. 27(4):973-977.

Grimmer K. and Williams M. (2000): Gender-age environmental associates of adolescent low back pain. Appl Ergon. 31(4):343-60.

Gray C., Burton L., Kiesel K., Rose G., Bryant M.F. (2010): Movement: Functional Movement Systems. On Target Publications. USA. p87-106.

Haag S.J., Wright G.A. Gillette C.M. Greany J..F. (2010): Effects of acute static stretching of the throwing shoulder on pitching performance of national collegiate athletic association division II baseball players. J Strength Cond Res. 24(2):452-7.

Haddad M., Dridi A., Chtara M., Chaouachi A., Wong del P., Behm, D., Chamar K. (2014): Static stretching can impair explosive performance for at least 24 hours. J Strength Cond Res. 28(1):140-6.

Haugstad G.K. Haugstad T.S., Kirste U.M., Leganger S., Wojniusz S., Klemmetsen I., Malt U.F. (2006): Posture, movement patterns, and body awareness in women with chronic pelvic pain. J Psychosom Res. 61(5):637-44.

Holth H.S., Werpen H.K.B., Zwart J.A., Hagen K. (2008): Physical inactivity is associated with chronic musculoskeletal complaints 11 years later: Results from the Nord-Trondelag Health Study. BMC Musculoskel Disord. 9:159.
Hirth, C.J. (2007): Clinical Movement Analysis to identify Muscle Imbalances and Guide Exercise. ATT 12(4):10-14

Murphy S., Buckle P., Stubbs D. (2004): Classroom posture and self-reported back and neck pain in schoolchildren. Appl Ergon. 35(2):113-120.

Janda, V. (1987): Muscles and motor control in low back pain: Assessment and management. In Physical Therapy of the low back, ed. L.T.Twomey, Churchill Livingstone. New York. p253-78.

Judge L.W., Craig B., Baudendistal S., Bodey K.J. (2009): An examination of the stretching practices of Division I and Division III college football programs in the midwestern United States. J Strength Cond Res. 23:1091-1096.

Kendall F.P., McKCreary E.K. and Provance P.G. (2005): Muscle Testing and Function with Posture and Pain. $5^{\text {th }}$ ed. Lippincott Williams and Wilkins, Baltimore, MD. p.50-54.

Machado de Rezende L.F., Lopes M.R. Rey-López J.P., Keihan V., Matsudo R., Olinda do Carmo Luiz. (2014): Sedentary behavior and health outcomes among older adults: a systematic review. Epub. 2014. 21(8):9.

Marek S.M., Cramer J.T., Fincher A.L., Massey L.L., Dangelmaier S.M., Purkayastha S., Fitz K.A., Culbertson J.Y. (2005): Acute Effects of Static and Proprioceptive Neuromuscular Facilitation Stretching on Muscle Strength and Power Output. J Athl Train. 40(2):94-103.

Mense, S. and Simons D.G. (2001): Muscle pain: Understanding its nature, diagnosis, and treatment. Pain associated with increased muscle tension. Lippincott Williams \& Wilkins, Baltimore.
Page P., Clare C.F., and Ladner R. (2010): Assessment and Treatment of Muscle Imbalance. The Janda Approach. Human Kinetics, p50-54,123.

Paradisis G.P., Pappas P.T. Theodorou A.S., Zacharogiannis E.G, Skordilis E.K. Smirniotou A.S. (2014): Effects of static and dynamic stretching on sprint and jump performance in boys and girls. J Strength Cond Res. 25(7):1925-1931.

Peres S.E., Draper D.O., Knight K.L. Ricard M.D. (2002): Pulsed short waved diathermy and prolonged long duration stretching increase dorsiflexion range of motion more than identical stretching without diathermy. J Athl Train. 37(1):43-50

Pope R.P., Herbert R.D., Kirwan J.D. (1998): Effects of ankle dorsiflexion range and pre-exercise calf muscle stretching on injury risk army recruits. Australian $\mathrm{J}$ Physio. 44:165-177.

Wilson J.M., Hornbuckle L.M., Kim J.S., Ugrinowitsch C., Lee S.R., Zourdos M.C., Sommer B., Panton L.B. (2010): Effects of static stretching on energy cost and running endurance performance. J Strength Cond Res. 24(9):2274-9.

Yu B., McClure S.B., Onate J.A., Guskiewicz K.M., Kirkendall D.T., Garrett Jr. W.E. (2005): Age and 7 gender effects on lower extremity kinematics of youth soccer players in a stop-jump task. Am J Sports Med. 33(9):1356- 1364.

FMS:http://www functionalmovement.com/site/systemdefined

NASM CEx: http://www.sport981. com/pdfs/NASM\%20Corrective\%20Exericse $\% 20$ Specialist $\% 20$ Sample $\% 20$ Chapter. pdf 